\title{
Comparison of functional outcome of ultrasound guided glenohumeral and subacromial methylprednisolone acetate injections in frozen shoulder
}

\author{
Mayur Chopra ${ }^{1}$, Attique $\operatorname{Vasdev}^{2}$
}

\begin{abstract}
${ }^{1}$ Resident doctor, DNB Orthopaedics, ${ }^{2}$ Director, Department of orthopaedics, Medanta-The Medicity, Gurgaon, Haryana, India
\end{abstract}

Received: 05 October 2018

Revised: 21 October 2018

Accepted: 23 October 2018

\section{*Correspondence:}

Dr. Mayur Chopra,

E-mail: mayurc18@gmail.com

Copyright: $\odot$ the author(s), publisher and licensee Medip Academy. This is an open-access article distributed under the terms of the Creative Commons Attribution Non-Commercial License, which permits unrestricted non-commercial use, distribution, and reproduction in any medium, provided the original work is properly cited.

\section{ABSTRACT}

Background: Frozen shoulder also known as adhesive capsulitis is a common cause for limitation of motion and pain of the shoulder joint with an incidence of $2-5 \%$ in the general population. The aim of the study was to assess the functional outcome of ultrasound guided glenohumeral and subacromial methylprednisolone acetate steroid injection in patients with frozen shoulder.

Methods: 120 patients with frozen shoulder were randomly divided into 2 groups according to site i.e. glenohumeral and subacromial. Ultrasound-guided methylprednisolone acetate $(80 \mathrm{mg})$ injection was administered. At follow up pain was being measured using VAS scale and functional outcome was measured using the DASH score and Constant score at day 0,1 followed by $1,3,6$ weeks and at 3 months.

Results: The VAS score of glenohumeral decreased from $6.5 \pm 0.95$ to $2.25 \pm 0.86$ at 3 months and in subacromial it decreased from $6.37 \pm 1.07$ to $2.3 \pm 0.72$. DASH score in glenohumeral group decreased from $66.95 \pm 9.9$ to $27.45 \pm 9.31$ at 3 months and in the subacromial group it decreased from $67.52 \pm 10.65$ to $26.81 \pm 11.14$ at 3 months. In glenohumeral group Constant score increased from $46.63 \pm 7.18$ to $72.66 \pm 7.38$ at 3 months and in the subacromial group it increased from $47.92 \pm 6.91$ to $70.28 \pm 6.97$ at 3 months.

Conclusions: Spontaneous recovery does not necessarily occur even after a long period, so we recommend that these modalities should be offered to all patients with frozen shoulder and it would be of more value if carried out at an early stage of the disorder.

Keywords: Frozen shoulder, Adhesive capsulitis, Methylprednisolone, Ultrasound guided injection, Glenohumeral, Subacromial

\section{INTRODUCTION}

Frozen shoulder syndrome is said to exist in the presence of a soft tissue capsular lesion accompanied by pain and restricted active and passive motion at the glenohumeral joint. This disorder is one of the most common musculoskeletal problems seen in orthopaedics. Historically frozen shoulder has been regarded as a condition from which "recovery is always sure and may be confidently expected". Several investigators using a variety of treatment methods have reported that a high percentage of affected patients obtain a full range of motion of the shoulder as well as complete or nearly complete relief of symptoms.

Adhesive capsulitis has an incidence of $2-5 \%$ in the general population and up to $20 \%$ in those with diabetes, with subsequent involvement of the contralateral shoulder 
estimated to occur in 5-40\% of affected people. ${ }^{1,2}$ Increased incidence of frozen shoulder is seen in the female gender, age older than 49 years, diabetes mellitus (five times more), cervical disc disease, prolonged immobilization, hyperthyroidism, stroke or myocardial infarction, the presence of autoimmune diseases, and trauma. $^{3}$ The condition rarely recurs in the same shoulder. $^{4}$

No definitive aetiology is known but it is found to be associated with many conditions, especially diabetes. ${ }^{1,3}$ It is found to be associated with IL- $1 \alpha$, IL- $1 \beta$, TNF- $\alpha$, COX-1, and COX-2 which are expressed at significantly higher levels in the joint capsules of the frozen shoulder. Twin studies have shown that adhesive capsulitis occurs 2 to 3 times more frequently than by chance. ${ }^{6}$

Pathologically the disease is characterised by retraction and thickening of the joint capsule and decreased volume of joint fluid. Diagnosis of frozen shoulder is mainly clinical and radiographic studies are used to exclude other causes of shoulder pain like rotator cuff disease, arthritis $\&$ calcific tendinitis.

Frozen shoulder diagnosis is done by clinical history and local examination and patient presents with pain and restriction of passive shoulder movements, particularly rotation, abduction and forward flexion. ${ }^{7,8}$

Treatment options include NSAIDS, physical therapy and exercises, intraarticular steroid injection, hydraulic distension, blockade of the suprascapular nerve, manipulation under anaesthesia, arthroscopic release and skilful neglect. ${ }^{9-21}$ The rationale for injection of an intra articular steroid derivative is to allow direct delivery of a modest dose of corticosteroid with analgesic and antiinflammatory properties to the targeted site of pathology.

There is insufficient data to strongly prove any added benefit of image guided steroid injections on shoulder outcomes, hence this study was undertaken to differentiate between the effects of ultrasound guided intracapsular (glenohumeral) and extracapsular (subacromial) methylprednisolone acetate steroid injection in patients with frozen shoulder. The reason for injecting steroid under imaging is to reduce the chances of error. ${ }^{22}$

It is important in developing countries to find a cost effective and safe procedure to reduce the morbidity of the condition. This study aims at identifying the best and most effective method among the above mentioned options by evaluating functional outcome of each modality. These procedures will be carried as outdoor procedures.

\section{METHODS}

This study was a prospective comparative study carried out in the outpatient department of orthopaedics at
Medanta - The Medicity, Gurgaon, India over a period of 6 months from September 2016 to February 2017. A total of 120 patients with primary idiopathic adhesive capsulitis were enrolled in the study with prior informed consent and patients with post traumatic stiff shoulder, calcific tendinitis, acromioclavicular joint arthritis, rotator cuff disease, paediatric age group, hemiplegia, uncontrolled diabetes mellitus, previous operation and intra-articular steroid injection within 6 months, stiff shoulder secondary to brachial plexopathy were excluded from the study.

The patients were divided into two groups by randomisation and were administered a single shot of Ultrasound guided (4-12 Hz linear probe) $80 \mathrm{mg}$ methylprednisolone acetate steroid injection $+2 \mathrm{ml}$ of $2 \%$ lidocaine under strict aseptic precautions.

Follow up was conducted at day $1 ; 1^{\text {st }}, 3^{\text {rd }}, 6^{\text {th }}$ weeks and at 3 months. Pain was measured using VAS scale and functional outcome was measured using DASH score and Constant score. ${ }^{23-25}$ The blood glucose levels were also monitored.

\section{Statistical analysis}

The analysis included profiling of patients on different demographic and hemodynamic parameters. Descriptive analysis of quantitative parameters was expressed as means and standard deviation. The independent Student $t$ test was used for drawing inferences between groups and paired Student t test was used for drawing inferences within the group. Cross tables were generated and chi square test was used for comparisons and associations. The P-value $<0.05$ was considered statistically significant. All analysis was done using SPSS version, 24.0.

\section{RESULTS}

In our study, average age of patients was 60.25 in $\mathrm{GH}$ group and 58.43 in SA group. About $45.8 \%$ of patients were in between 51-60 years. Oldest patient in our study was 78 years old and youngest patient was 40 years old.

In our study, we noted a female predominance with affected females being $63.3 \%$ of total affected patients. The female: male ratio was $1.72: 1$ overall. The percentage of non-dominant limb involvement was $48.3 \%$ with $36.67 \%$ right side involvement and $63.33 \%$ left side involvement.

Hyperglycaemia is a known complication seen with steroid therapy, hence blood glucose levels were monitored and the random blood glucose levels were observed to be more in the glenohumeral group till 3 weeks as compared to subacromial group. It increased from $131.48 \pm 24.12$ pre-op to $160.45 \pm 31.01$ in the glenohumeral group and from $138.1 \pm 17.41$ to $153.87 \pm 18.81$ in the subacromial group. However, there 
was not much difference in the blood glucose levels

between the 2 groups at 6 weeks and 3 months

Table 1: DASH score comparison between glenohumeral (GH) and subacromial (SA) groups on follow up.

\begin{tabular}{|lllllll|}
\hline $\begin{array}{l}\text { Follow-up } \\
\text { period }\end{array}$ & $\begin{array}{l}\text { GH group } \\
\text { Mean } \pm \text { SD }\end{array}$ & P-value & Mean \pm SD & P-value & Mean \pm SD & P-value \\
\hline Pre Op & $66.95 \pm 9.9$ & & $67.52 \pm 10.65$ & & $67.23 \pm 10.24$ & \\
\hline Day 1 & $62.44 \pm 8.95$ & $<0.0001^{*}$ & $62.22 \pm 10.14$ & $<0.0001^{*}$ & $62.33 \pm 9.51$ & $<0.0001^{*}$ \\
\hline 1 Wk & $55.95 \pm 8.38$ & $<0.0001^{*}$ & $55.52 \pm 9.68$ & $<0.0001^{*}$ & $55.74 \pm 9$ & $<0.0001^{*}$ \\
\hline 3 Wks & $43.04 \pm 8.6$ & $<0.0001^{*}$ & $43.47 \pm 9.47$ & $<0.0001^{*}$ & $43.25 \pm 8.99$ & $<0.0001^{*}$ \\
\hline 6 Wks & $33.25 \pm 8.55$ & $<0.0001^{*}$ & $33.57 \pm 10.47$ & $<0.0001^{*}$ & $33.4 \pm 9.49$ & $<0.0001^{*}$ \\
\hline 3 Mths & $27.45 \pm 9.31$ & $<0.0001^{*}$ & $26.81 \pm 11.14$ & $<0.0001^{*}$ & $27.14 \pm 10.2$ & $<0.0001^{*}$ \\
\hline
\end{tabular}

$* \mathrm{p}$ value $>0.05$ is considered to be significant.

Table 2: Constant score comparison between glenohumeral (GH) and subacromial (SA) groups on follow up.

\begin{tabular}{|lllllll|}
\hline $\begin{array}{l}\text { Follow-up } \\
\text { period }\end{array}$ & GH group & & SA group & \multicolumn{3}{c|}{ Total } \\
\hline Pre Op & Mean \pm SD & P-value & Mean \pm SD & P-value & Mean \pm SD & P-value \\
\hline Day 1 & $54.63 \pm 7.18$ & & $47.92 \pm 6.91$ & & $47.28 \pm 7.05$ & \\
\hline 1 Wk & $60.8 \pm 7.63$ & $<0.0001 *$ & $60.91 \pm 6.63$ & $<0.0001^{*}$ & $60.85 \pm 7.12$ & $<0.0001 *$ \\
\hline 3 Wks & $69 \pm 6.79$ & $<0.0001 *$ & $66.17 \pm 6.95$ & $<0.0001^{*}$ & $67.62 \pm 6.98$ & $<0.0001 *$ \\
\hline 6 Wks & $71.2 \pm 7.09$ & $<0.0001 *$ & $69.08 \pm 6.57$ & $<0.0001 *$ & $70.17 \pm 6.89$ & $<0.0001 *$ \\
\hline 3 Mths & $72.66 \pm 7.38$ & $<0.0001 *$ & $70.28 \pm 6.97$ & $<0.0001^{*}$ & $71.5 \pm 7.25$ & $<0.0001 *$ \\
\hline
\end{tabular}

$* p$ value $>0.05$ is considered to be significant.

Table 3: VAS score comparison between glenohumeral (GH) and subacromial (SA) groups on follow up.

\begin{tabular}{|lllllll|}
\hline $\begin{array}{l}\text { Follow-up } \\
\text { period }\end{array}$ & $\begin{array}{l}\text { GH group } \\
\text { Mean } \pm \text { SD }\end{array}$ & P-value & Mean \pm SD & P-value & Mean \pm SD & P-value \\
\hline Pre Op & $6.5 \pm 0.95$ & & $6.37 \pm 1.07$ & & $6.43 \pm 1.01$ & \\
\hline Day 1 & $4.21 \pm 0.62$ & $<0.0001^{*}$ & $4.33 \pm 0.85$ & $<0.0001^{*}$ & $4.27 \pm 0.74$ & $<0.0001 *$ \\
\hline 1 Wk & $3.82 \pm 0.69$ & $<0.0001^{*}$ & $4.19 \pm 0.7$ & $<0.0001^{*}$ & $4 \pm 0.72$ & $<0.0001^{*}$ \\
\hline 3 Wks & $3 \pm 1.01$ & $<0.0001^{*}$ & $3.96 \pm 0.83$ & $<0.0001^{*}$ & $3.47 \pm 1.04$ & $<0.0001 *$ \\
\hline 6 Wks & $2.64 \pm 0.94$ & $<0.0001^{*}$ & $2.68 \pm 0.96$ & $<0.0001^{*}$ & $2.66 \pm 0.94$ & $<0.0001 *$ \\
\hline 3 Mths & $2.25 \pm 0.86$ & $<0.0001^{*}$ & $2.3 \pm 0.72$ & $<0.0001^{*}$ & $2.28 \pm 0.79$ & $<0.0001 *$ \\
\hline
\end{tabular}

*p value $>0.05$ is considered to be significant.

Complications seen in our study were nausea/vomiting in $0.05 \%$ patients of glenohumeral group and $0.016 \%$ patients in subacromial group and $0.016 \%$ patients in each group had a small episode of dizziness post injection. None of the other patients had any other complication.

\section{DISCUSSION}

Frozen shoulder is considered as a disease of middle aged persons between $4^{\text {th }}$ and $7^{\text {th }}$ decade. Aging plays an important role in pathogenesis of the disease due to lack of adequate use of shoulder, poor lifestyle and occurrence of non-insulin dependent diabetes mellitus.

A study done by Milgrom et al also showed female predominance for frozen shoulder similar to our study. ${ }^{26}$ But in our study the functional outcome was not influenced by the age and sex distribution among the patients.
Diabetes is a known risk factor associated with frozen shoulder and in our series out of 120 patients, 31 patients were diabetic $(25.8 \%)$ which was similar to study of Carette et al $(27.9 \%)$ out of 93 patients and Weber et al $[34.8 \%] .{ }^{27}$ But some other authors found relatively lower distribution of diabetes among patients. Shaffer et al found only 3 out of 62 patients to be diabetic in his study and Uddin found $42.5 \%$ of the patients with adhesive capsulitis to be diabetic. $^{28,29}$

An association between thyroid disease and frozen shoulder remains undetermined, but in our study, we found 31 patients $(25.8 \%)$ to be suffering from hypothyroidism, which is similar to the study by Schiefer et al which found $27.2 \%$ of the 93 frozen shoulder patients to be suffering from hypothyroidism. ${ }^{30}$

The disabilities of the arm, shoulder and hand (DASH) score significantly decreased in both the groups in this study at each follow up which is similar to the study by Buchbinder in 2004 which showed decrease in DASH 
score at each follow up for 3 months after short course prednisolone therapy. ${ }^{9}$ In glenohumeral group it decreased from $66.95 \pm 9.9$ to $27.45 \pm 9.31$ at 3 months and in the subacromial group it decreased from $67.52 \pm 10.65$ to $26.81 \pm 11.14$ at 3 months. Hence there was no significant difference in DASH score between the two groups at each follow up.

The Constant score was found to be increasing in both the groups. In the glenohumeral group it increased from $46.63 \pm 7.18$ to $72.66 \pm 7.38$ at 3 months and in the subacromial group it increased from $47.92 \pm 6.91$ to $70.28 \pm 6.97$ at 3 months. Hence there is significant increase in Constant score in both the groups but there is no significant difference between the 2 groups till 1 week but after 3 weeks glenohumeral group showed better Constant scores than subacromial group. Similar Study by Oh et al in 2011 showed decrease in Constant score in both the groups at every follow up but found no significant difference between the two groups at each follow up. ${ }^{31}$

In our study, we used the VAS (visual analogue scale) for pain measurement. The VAS score improvement was evident in both the groups at each follow up. In glenohumeral it decreased from $6.5 \pm 0.95$ to $2.25 \pm 0.86$ at 3 months and in subacromial it decreased from $6.37 \pm 1.07$ to $2.3 \pm 0.72$. The GH group showed lower pain VAS at 3 weeks, but no statistical difference was found between the 2 groups at 6 and 3 months. Study by Oh et al in 2011 showed similar findings. ${ }^{31}$

In their study of management of painful shoulder with intra articular steroid injection Bulgen et al included 55 and 42 patients respectively, with painful limitation of all shoulder movement and pain at night similar to the patients of our study. ${ }^{32}$

As a limitation we did not include a control group receiving other treatment modalities, such as physiotherapy with medication or a placebo injection to eliminate the possibility that a placebo effect was responsible for the improvements.

Frozen shoulder is a debilitating condition, but faster symptomatic relief decreases long term morbidity and earlier returns to normal day to day activity. These are key points in the adoption of these modalities for treatment of frozen shoulder.

Funding: No funding sources

Conflict of interest: None declared

Ethical approval: The study was approved by the Medanta Institute of Ethical Committee, Medanta-The Medicity Gurgaon

\section{REFERENCES}

1. Bridgman JF. Periarthritis of the shoulder and diabetes mellitus. Ann Rheum Dis 1972;31:69-71.

2. Buchbinder R, Green S. Effect of arthrographic shoulder joint distension with saline and corticosteroid for adhesive capsulitis. Br J Sports Med. 2004;38(4):384-5.

3. Wolf JM, Green A. Influence of comorbidity on self-assessment instrument scores of patients with idiopathic adhesive capsulitis. J Bone Joint Surg Am. 2002;84:1167-73.

4. Canale ST, Beaty JH. Campbell operative orthopaedics. 12th ed. Volume 3. Elsevier Mosby; 2012: 2235.

5. Lho Y-M, Ha E, Cho C-H, Song K-S, Min B-W, Bae K-C, et al. Inflammatory cytokines are overexpressed in the subacromial bursa of frozen shoulder. Journal of Shoulder and Elbow Surgery. 2013;22(5):666-72.

6. Hakim AJ, Cherkas LF, Spector TD, MacGregor AJ. Genetic associations between frozen shoulder and tennis elbow: a female twin study. Rheumatology (Oxford). 2003;42(6):739-42.

7. Neviaser AS, Hannafin JA. Adhesive Capsulitis A Review of Current Treatment. Am J Sports Med. 2010;38(11):2346-56.

8. Weinstein SL, Buckwalter JA. Turek's Orthopaedics, Principles and Their Application. Philadelphia, PA: JB Lippincott Company; 1994.

9. Buchbinder R, Hoving JL, Green S, Hall S, Forbes A, Nash P. Short course prednisolone for adhesive capsulitis (frozen shoulder or stiff, painful shoulder): a randomised, double blind, placebo controlled trial. Ann Rheum Dis. 2004;63(11):1460-9.

10. Griggs SM, Ahn A, Green A. Idiopathic adhesive capsulitis. A prospective functional outcome study of nonoperative treatment. J Bone Joint Surg Am. 2000;82(10):1398-407.

11. Levine WN, Kashyap CP, Bak SF, Ahmad CS, Blaine TA, Bigliani LU. Nonoperative management of idiopathic adhesive capsulitis. J Shoulder Elbow Surg. 2007;16:569-73.

12. Carette S, Moffet H, Tardif J, Bessette L, Morin F, Fremont $\mathrm{P}$, et al. Intraarticular corticosteroids, supervised physiotherapy, or a combination of the two in the treatment of adhesive capsulitis of the shoulder: a placebo-controlled trial. Arthritis Rheum. 2003;48:829-38.

13. Ryans I, Montgomery A, Galway R, Kernohan WG, McKane R. A randomized controlled trial of intraarticular triamcinolone and/or physiotherapy in shoulder capsulitis. Rheumatology (Oxford). 2005;44(4):529-35.

14. Weiss JJ, Ting YM. Arthrography-assisted intraarticular injection of steroids in treatment of adhesive capsulitis. Arch Phys Med Rehabil. 1978;59:285-7. 
15. Dahan TH, Fortin L, Pelletier M, Petit M, Vadeboncoeur R, Suissa S. Double blind randomized clinical trial examining the efficacy of bupivacaine suprascapular nerve blocks in frozen shoulder. J Rheumatol. 2000;27:1464-9.

16. Jones DS, Chattopadhyay C. Suprascapular nerve block for the treatment of frozen shoulder in primary care: a randomized trial. Br J Gen Pract. 1999;49:39-41.

17. Dodenhoff RM, Levy O, Wilson A, Copeland SA. Manipulation under anesthesia for primary frozen shoulder: effect on early recovery and return to activity. J Shoulder Elbow Surg. 2000;9:23-6.

18. Farrell CM, Sperling JW, Cofield RH. Manipulation for frozen shoulder: long-term results. J Shoulder Elbow Surg. 2005;14:480-4.

19. Holloway GB, Schenk T, Williams GR, Ramsey ML, Iannotti JP. Arthroscopic capsular release for the treatment of refractory postoperative or postfracture shoulder stiffness. J Bone Joint Surg Am. 2001;83:1682-7.

20. Berghs BM, Sole-Molins X, Bunker TD. Arthroscopic release of adhesive capsulitis. J Shoulder Elbow Surg. 2004;13:180-5.

21. Diercks RL, Stevens M. Gentle thawing of the frozen shoulder: a prospective study of supervised neglect versus intensive physical therapy in seventyseven patients with frozen shoulder syndrome followed up for two years. J Shoulder Elbow Surg. 2004;13:499-502.

22. Soh E, Li W, Ong KO, Chen W, Bautista D. Imageguided versus blind corticosteroid injections in adults with shoulder pain: A systematic review. BMC Musculoskeletal Disorders. 2011;12:137.

23. McCormack HM, Horne DJ. Sheather Clinical applications of visual analogue scales: a critical review Psychol Med. 1988;18(4):1007-19.

24. Constant CR, Murley AH. A clinical method of functional assessment of the shoulder. Clin Orthop Relat Res. 1987;(214):160-4.
25. Gummesson C, Atroshi I, Ekdahl C. The disabilities of the arm, shoulder and hand (DASH) outcome questionnaire: longitudinal construct validity and measuring self-rated health change after surgery. BMC Musculoskeletal Disorders. 2003;4:11.

26. Charles M, Victor N, Yoram W, Saleh J, Denitsa, Aharon F. Risk Factors for Idiopathic Frozen Shoulder. IMAJ. 2008;10:361-4.

27. Weber M, Prim J, Bugglin R, Michel BA, Gerber H. Long term follow up of patients with frozen shoulder. Clin Rheumatol. 1995;14:686-91.

28. Shaffer B, Tibone JE, Kerlan RK. Frozen shoulder. A long-term follow-up. JBJS AM. 1992;74:738-46.

29. Uddin MM, Khan AA, Haig AJ, Uddin MK. Presentation of frozen shoulder among diabetic and non-diabetic patients. J Clin Orthop Trauma. 2014;5(4):193-8.

30. Schiefer M, Teixeira PFS, Fontenelle C, Carminatti T, Santos DA, Righi LD, et al. Prevalence of hypothyroidism in patients with frozen shoulder. J Shoulder Elbow Surg. 2017;26(1):49-55.

31. Oh JH, Oh CH, Choi J-A, Kim SH, Kim JH, Yoon JP. Comparison of glenohumeral and subacromial steroid injection in primary frozen shoulder: a prospective, randomized short-term comparison study. J Shoulder Elbow Surg. 2011;20(7):1034-40.

32. Bulgen DY, Binder AI, Hazleman BL, Dutton J, Roberts S. Frozen shoulder: prospective clinical study with an evaluation of three treatment regimens. Ann Rheum Dis. 1984;43(3):353-60.

Cite this article as: Chopra M, Vasdev A. Comparison of functional outcome of ultrasound guided glenohumeral and subacromial methylprednisolone acetate injections in frozen shoulder. Int J Res Orthop 2018;4:876-80. 